Hydrol. Earth Syst. Sci., 17, 3371-3387, 2013

www.hydrol-earth-syst-sci.net/17/3371/2013/

doi:10.5194/hess-17-3371-2013

(c) Author(s) 2013. CC Attribution 3.0 License.

\title{
Physically based modeling of rainfall-triggered landslides: a case study in the Luquillo forest, Puerto Rico
}

\author{
C. Lepore ${ }^{1}$, E. Arnone ${ }^{2,4}$, L. V. Noto ${ }^{2}$, G. Sivandran ${ }^{3}$, and R. L. Bras ${ }^{4}$ \\ ${ }^{1}$ Parsons Laboratory for Environmental Science and Engineering, Department of Civil and Environmental Engineering, \\ Massachusetts Institute of Technology, Cambridge, MA, USA \\ ${ }^{2}$ Dipartimento di Ingegneria Civile, Ambientale, Aerospaziale, dei Materiali, Università degli Studi di Palermo, Palermo, Italy \\ ${ }^{3}$ Ohio State University, Department of Civil, Environmental and Geodetic Engineering 483B Hitchcock Hall, \\ 2070 Neil Avenue, Columbus, OH 43210, USA \\ ${ }^{4}$ Georgia Institute of Technology, Atlanta, GA, USA
}

Correspondence to: C. Lepore (chlepore@mit.edu) and E. Arnone (elisa.arnone@unipa.it)

Received: 5 December 2012 - Published in Hydrol. Earth Syst. Sci. Discuss.: 28 January 2013

Revised: 11 July 2013 - Accepted: 12 July 2013 - Published: 3 September 2013

\begin{abstract}
This paper presents the development of a rainfalltriggered landslide module within an existing physically based spatially distributed ecohydrologic model. The model, tRIBS-VEGGIE (Triangulated Irregular Networks-based Real-time Integrated Basin Simulator and Vegetation Generator for Interactive Evolution), is capable of a sophisticated description of many hydrological processes; in particular, the soil moisture dynamics are resolved at a temporal and spatial resolution required to examine the triggering mechanisms of rainfall-induced landslides. The validity of the tRIBS-VEGGIE model to a tropical environment is shown with an evaluation of its performance against direct observations made within the study area of Luquillo Forest.

The newly developed landslide module builds upon the previous version of the tRIBS landslide component. This new module utilizes a numerical solution to the Richards' equation (present in tRIBS-VEGGIE but not in tRIBS), which better represents the time evolution of soil moisture transport through the soil column. Moreover, the new landslide module utilizes an extended formulation of the factor of safety (FS) to correctly quantify the role of matric suction in slope stability and to account for unsaturated conditions in the evaluation of FS.

The new modeling framework couples the capabilities of the detailed hydrologic model to describe soil moisture dynamics with the infinite slope model, creating a powerful tool for the assessment of rainfall-triggered landslide risk.
\end{abstract}

\section{Introduction}

Landslides represent one of the most important landformshaping process. All 50 states in the United States have recorded some landslide activity with minor or major socioeconomic consequences (Schuster and Highland, 2001; Swanston and Schuster, 1989). Human activity has accelerated the occurrence of landslides by modifying vegetation distribution (i.e., root-soil cohesion), altering the hydrologic regime and disrupting the natural equilibrium. Recent studies of the impacts from landslide activity in the US alone predict 25-50 deaths per year and an annual average total cost of up to $\$ 3.2$ billion (including direct and indirect costs) (Sidle and Ochiai, 2006)

Landslides are categorized by both the mode of movement as well as the material being transported during an event. Some movements are connected to specific climatic triggering factors, such as rainfall. These movements are generally shallow and rapid when triggered by large precipitation events on slopes with wet antecedent conditions - deeper and slower when the accumulated precipitation volume gradually builds over an extended time period, eventually leading to stability failure. This study focuses primarily on very fast and shallow earth displacements triggered by intense and short rainfall events, such as debris slides (Sidle and Dhakal, 2002). For these movements, the assumption that the failure plane is oriented approximately parallel to the soil surface can be accepted, allowing for the use of the infinite 
slope hypothesis, which introduces greater simplification to the modeling process.

The initiation of rainfall-triggered landslides is strongly coupled to various hydrological processes, which impact the mechanisms that ultimately cause slope failures. Hydrologic triggering of landslides is a result of both a decrease in the shear strength due to an increase of pore-water pressure and an increase of the soil weight that increases the destabilizing forces on a slope. For these reasons, the knowledge of spatiotemporal dynamics of soil water content, groundwater, infiltration and vegetation processes are of considerable importance for the understanding and prediction of landslides (De Vita et al., 1998).

The most common practice followed when developing landslide forecasting models is to couple the hydrological model with a stability model to assess the factor of safety (FS). The infinite slope model is commonly used in the literature (Arnone et al., 2011; Burton and Bathurst, 1998; Capparelli and Versace, 2010; Montgomery and Dietrich, 1994; Pack et al., 1998; Rosso et al., 2006; Simoni et al., 2008; Wu and Sidle, 1995). It assumes that the plane of failure is parallel to the slope, resulting in a static well-defined equation for the calculation of FS (Taylor, 1948).

Most models can be grouped according to two main features: (1) the hydrological framework used to describe the soil moisture dynamics, i.e., based on a modified approach of wetness index (Arnone et al., 2011; Borga et al., 2002; Burton and Bathurst, 1998; Claessens et al., 2007; Montgomery and Dietrich, 1994; Pack et al., 1998) or based on an approximation of Richards' equation (Baum et al., 2002; Capparelli and Versace, 2010; Iverson, 2000; Simoni et al., 2008; Tsai and Yang, 2006); and (2) the failure criterion used to derive the FS equation, which sometime accounts for unsaturated conditions (Meisina and Scarabelli, 2007; Montrasio and Valentino, 2008; Yeh et al., 2006) or not (Arnone et al., 2011; Tarolli et al., 2011; Simoni et al., 2008; Baum et al., 2002; Iverson, 2000; Burton and Bathurst, 1998; Pack et al., 1998; Montgomery and Dietrich, 1994).

A detailed description of the literature and the infinite slope model equations are provided in Arnone (2011) and Arnone et al. (2011). The approach used in these two works is based on a modified formulation of the relative wetness index (Montgomery and Dietrich, 1994) as a function of soil moisture in the unsaturated zone and water table dynamics. This methodology neglects the cohesive effect of negative pore pressure, i.e., matric suction, of unsaturated soils, which should be accounted for in the failure criterion. In fact, some failure events can be caused solely by the decrease of matric suction occurring after a rainfall event (Lu and Godt, 2008). The approach proposed by Iverson (2000), based on the Richards' equation, tried to overcome this limitation by introducing matric suction into the FS equation. However, since the failure criterion is still based on a either dry or fully saturated scheme, this approach can lead to errors in the calculation of the FS.
In recent years, several procedures have been proposed to predict the shear strength of unsaturated soil using the extended Mohr-Coulomb failure criterion of Bishop (1955) (Vanapalli et al., 1996; Fredlund et al., 1996; Khallili and Khabbaz, 1998; Oberg and Sallfors, 1997; Bao et al., 1998).

These formulations use the soil-water characteristic curve to predict the shear strength function for an unsaturated soil, in addition to saturated shear strength, cohesion and friction angle. The physical properties of the soil, such as texture and pore-size distribution, become very important in the factor of safety dynamics.

This work builds on the previous version of the tRIBS (Triangulated Irregular Network-based Real-time Integrated Basin) landslide component (Arnone et al., 2011). The main differences with the previous version are both in the soil moisture dynamics model and in the failure model. First, the tRIBS-VEGGIE (Vegetation Generator for Interactive Evolution), compared to tRIBS, utilizes a numerical solution to the Richards' equation to better represent the time evolution of soil moisture transport through the soil column, resulting in a more accurate representation of the soil moisture profile. Particular attention is given to both vertical and lateral redistribution, and most of those hydrologic factors important in the assessment of landslides are resolved. Secondly, the landslide module is extended using the Bishop formulation to correctly quantify the role of matric suction in slope stability and to account for unsaturated conditions in the evaluation of FS.

Being a process-driven model, it can be applied to any type of basin where weather data and basic soil information exist. This model can be utilized to test different rainfall scenarios at the catchment scale to identify high-risk storm characteristics; in the future, when more data and measurements will be available, it can possibly be integrated into an early warning system. Because of its vegetation component, the model can be also used to test the effects of land use changes in terms of hydrologic regime's variations and its effects on slope stability.

The newly developed model is here used in the Rio Mameyes Basin, Puerto Rico. This basin displays particular features that make the territory prone to landslides (Larsen and Simon, 1993; Larsen and Torres-Sánchez, 1998, 1992; Lepore et al., 2012; Larsen and Parks, 1997). Particularly, the application presented in this manuscript stresses the importance of correctly modeling the soil moisture dynamics in the analysis of rainfall-triggered landslides, and evaluates the effects of soil hydrological properties on slope stability.

The structure of the manuscript is the following: in Sect. 2 we introduce the two main components of the model, and in Sect. 3 the study area. Section 4 describes the data used in both the validation and in the modeling exercise. Section 5 shows the results of a model validation based on direct observation of soil moisture. Section 6 reports an in-depth analysis and discussion of the response of the model to an intense 
rainfall event both at point and catchment scale. Section 7 concludes the manuscript.

\section{Methods}

\subsection{Physically distributed hydrology model: tRIBS-VEGGIE}

The tRIBS-VEGGIE is an eco-hydrological model that consists of a spatially distributed physically based hydrological model coupled to a model of plant physiology and spatial dynamics (Ivanov et al., 2008a, b; Sivandran, 2012).

The tRIBS model has the capability to explicitly consider the spatial variability in precipitation fields, land-surface descriptors and the corresponding moisture dynamics, stressing the role of topography in lateral soil moisture redistribution and accounting for the effects of heterogeneous and anisotropic soil. Basin hydrological response can be simulated at very fine temporal (subhourly) resolution and on an irregular spatial mesh $(10-1000 \mathrm{~m})$. The irregular mesh allows for the use of smaller computational elements to represent regions within the basin of interest while using larger elements for less critical regions. This framework offers a flexible and reliable computational structure that reduces the number of computational elements without significant loss of information (Vivoni et al., 2005). Some of the hydrological components presented in the previous tRIBS model were modified; the most critical to this study is in relation to the infiltration scheme. The original tRIBS is based on the kinematic wave approximation of Cabral et al. (1992) and Garrote and Bras (1995), which models the evolution of the wetting front and top front and leads to four saturation states (unsaturated, perched, surface and completely saturated); this framework was used for the development of the previous version of landslide module (Arnone et al., 2011) and as well as of an erosion module (Francipane et al., 2012). The tRIBSVEGGIE model instead is based on a numerical approximation of the one-dimensional Richards' equation (Hillel, 1980) that governs the fluid flow into the unsaturated soil.

The dynamics of each computational element are simulated separately, but spatial dependencies are introduced by considering the surface and subsurface moisture transfers among the elements; within each soil layer of a cell, the subsurface flux is redistributed to the corresponding layer of the receiving cell along the direction of steepest descent based upon the unsaturated hydraulic conductivity of the latter one, which affects local dynamics via the coupled energy-water interactions. The unsaturated hydraulic characteristics, both in terms of hydraulic conductivity and soil water potential, are related to soil-moisture content through the Brooks and Corey (1964) parameterization scheme (Ivanov, 2006; Sivandran and Bras, 2012), as a function of the saturated hydraulic conductivity in the normal to the soil surface direction, the air entry bubbling pressure and the pore-size distribution index.
Consequently, when applied to a catchment, the model offers a quasi-three-dimensional framework by which lateral moisture transfers and difference in topographic characteristics may lead to the spatio-temporal variability of states (Ivanov et al., 2008b).

VEGGIE models the spatial distribution of vegetation types (e.g., trees vs. grasses) and pertinent properties of the vegetation state (e.g., vegetation fraction, leaf area index, biomass, etc.) (Ivanov et al., 2008a, b), and enriches the hydrology model by accounting for vegetation characteristics that affect both water and energy balance dynamics. Above ground, the canopy has the ability to intercept and retain precipitation that affects the soil infiltration process, and the energy budget. Below ground, vegetation influences the vertical distribution of soil moisture via plant water uptake, and to the cohesion of the soil-bedrock-root matrix, depending on the distribution of roots. VEGGIE utilizes the plant functional type (PFT) vegetation classification scheme (Smith et al., 1997), and allows for a single computational element to simulate multiple PFTs that may differ in life form (e.g., tree, shrub, grass), vegetation physiology (e.g., leaf optical and photosynthetic properties) and structural attributes (e.g., height, leaf dimension or root), each interplaying differently with the hydrological response of the basin (Bonan et al., 2002). The coupled model can simulate biophysical energy processes (short- and long-wave radiation interactions, canopy and soil evaporation, energy flux partitioning and transpiration), biophysical hydrologic processes (interception, stemflow, infiltration, runoff, run-on and unsaturated zone flow) and biochemical processes (photosynthesis, plant respiration, tissue turnover, vegetation phenology and plant recruitment) (Ivanov et al., 2008a, b). The role of vegetation in this application is limited to the extraction of soil moisture for the purposes of transpiration. The dynamic model allows for a realistic representation of the controls of this soil moisture sink. Transpiration is primarily controlled by vapor pressure deficit, soil moisture levels, rooting profile, leaf area and available energy. For complete details on the transpiration parameterization, refer to Ivanov et al. (2008a) and Sivandran and Bras (2012).

\subsection{Slope stability module}

The stability model involves the assessment of FS by applying limit equilibrium analysis. The infinite slope model is commonly used in the literature, and it provides a welldetermined static equation for the calculation of FS (Taylor, 1948), as described in detail in Arnone et al. (2011). The approach used in Arnone et al. (2011) for the landslide module accounts for the soil moisture in the unsaturated zone and water table dynamics, but it neglects the effect of matric suction when computing FS and the corresponding shear strengths in unsaturated soils.

In the last decades, the literature has proposed new procedures to predict the shear strength of unsaturated soil 
(Vanapalli et al., 1996; Fredlund et al., 1996; Khallili and Khabbaz, 1998; Oberg and Sallfors, 1997; Bao et al., 1998) based on an extended failure criterion of Mohr-Coulomb, (Bishop, 1955), which utilizes the soil-water characteristic curve in addition to the saturated shear strength parameters (cohesion and friction angle). According to this formulation, the shear strength is expressed as

$\tau_{f}=c^{\prime}+\left(\sigma_{\mathrm{n}}-u_{\mathrm{a}}\right) \tan \varphi+\left(u_{\mathrm{a}}-u_{\mathrm{w}}\right) \chi(\tan \varphi)$,

where $\tau_{f}$ is the shear strength of unsaturated soil, $c^{\prime}$ is the effective cohesion, $\sigma_{\mathrm{n}}$ is the normal stress state on the failure plane, $u_{\mathrm{a}}$ is the air pressure and thus $\left(\sigma_{\mathrm{n}}-u_{\mathrm{a}}\right)$ is the net normal stress state on the failure plane, $\varphi$ is the friction angle, $u_{\mathrm{w}}$ is the water pressure and thus $\left(u_{\mathrm{a}}-u_{\mathrm{w}}\right)$ is the matric suction on the failure plane, and $\chi$ is a parameter that depends on the degree of saturation of the soil. The value of $\chi$ is assumed to vary from 1 to 0 , which represents the variation from a fully saturated condition to a completely dry condition. Several formulations have been developed to evaluate the $\chi$ term, and a comparative assessment of such formulations is provided by Vanapalli and Fredlund (2000). They considered three soil types and different ranges of matric suction to compare the measured and predicted values of unsaturated shear strength for each of the formulations, and investigate the performance for different soil types and matric suction ranges. It followed that performance of each formulation is more sensitive to the matric suction ranges than the type of soils. As soils approach the saturation, the performances are almost the same.

Vanapalli et al. (1996) parameterization is used for our study because of its simplicity. For a given soil the $\chi$ term is assumed to be equal to the effective saturation (i.e., a function of the volumetric water content $\theta$ and the residual and saturated soil moisture contents, $\theta_{\mathrm{r}}$ and $\theta_{\text {sat }}$, which are both parameters of the soil texture):

$\chi=\left(\frac{\theta-\theta \mathrm{r}}{\theta_{\mathrm{sat}}-\theta_{\mathrm{r}}}\right)$.

The FS equation can be derived by substituting Eq. (2) in Eq. (1) and using equilibrium of forces according to the infinite slope scheme. Then, assuming the pore-air pressure $u_{\mathrm{a}}=0$, and the pore-water pressure $u_{\mathrm{w}}$ as the product of unit weight of water $\left(\gamma_{\mathrm{w}}\right)$ and the pressure head $(\psi)$, the FS reduces to

$$
\begin{aligned}
\mathrm{FS} & =\frac{c^{\prime}}{\gamma_{\mathrm{s}} h \sin \alpha \cos \alpha} \\
& +\frac{\tan \varphi}{\tan \alpha}-\frac{\gamma_{\mathrm{w}} \psi}{\gamma_{\mathrm{s}} h} \cdot\left(\frac{\theta-\theta_{\mathrm{r}}}{\theta_{\mathrm{sat}}-\theta_{\mathrm{r}}}\right) \cdot \frac{\tan \varphi}{\sin \alpha \cos \alpha},
\end{aligned}
$$

where $h$ is the soil depth in the vertical direction and $\gamma_{\mathrm{s}}$ the averaged in depth total unit weight of soil. In unsaturated soils, $\psi$ is equal to the matric suction and is assumed negative. Equation (3) is equal to the equation proposed by Iverson (2000) but for the effective saturation term, not present in his work. In Eq. (3), this term modulates the overall contribution of the suction to FS, suggesting an overestimation of FS by the Iverson formulation. Under saturated conditions $\left(\theta=\theta_{\text {sat }}\right)$, the two approaches reduce to the same expression.

As a result of the multilayer representation of soil moisture within tRIBS-VEGGIE, the FS can be computed locally with no need to make an a priori hypothesis on the depth of the failure surface. The final product of the module is thus a spatially distributed vertical dynamic FS profile that takes into account the local moisture and soil conditions within the computational element: the first depth at which the condition FS $\leq 1$ is obtained is designated as the failure surface depth and consequently represents the depth used to estimate the volume of detached material. During a rainfall event, this modeling framework utilizes the soil moisture dynamics response to monitor the time evolution of FS, and, by setting different warning thresholds, can dynamically define a spatial distribution of instability levels of the basin.

\section{Study area}

The island of Puerto Rico is located in the northeastern Caribbean and is the smallest island of the Greater Antilles. With its roughly rectangular shape, the island is characterized topographically by flat coastal areas and two mountain ranges, the Cordillera Central, which spans east to west with a peak of $1338 \mathrm{~m}$, and the Sierra de Luquillo, which will be the focus of this study, with Pico del Este, or East Peak, at $1075 \mathrm{~m}$. The Sierra de Luquillo was chosen for this study as it contains the Luquillo Experimental Forest (LEF), which is part of both the Long Term Ecological Research (LTER) and of the Critical Zone Observatory (CZO) networks. This study will focus on the Rio Mameyes Basin (hereto referred to as "Mameyes Basin"), in the northeast of the Sierra de Luquillo and within the LEF boundaries (see Fig. 1). The LEF has been a focal point for studies in landslide impacts on ecology, geomorphology, biology, disturbance and recovery of vegetation (Myster et al., 1997; Scatena and Lugo, 1995; Shiels et al., 2008; Walker and Shiels, 2008; Walker et al., 1996). The Mameyes Basin was selected for the modeling effort based on the availability of specific data and parameters needed to implement tRIBS-VEGGIE.

The Mameyes Basin has an area of $16.7 \mathrm{~km}^{2}$, and is characterized by a rapid change in elevation from 104.2 to $1046 \mathrm{~m}$ across a horizontal distance of $3 \mathrm{~km}$. An analysis of the slope distribution derived from a DEM (digital elevation model) (see Fig. 2a and d) reveals $10 \%$ of the basin area being characterized by slopes greater than $30^{\circ}$ and $30 \%$ of the basin area with slopes greater than $25^{\circ}$ (see Table 1). The climate of the island is controlled by the easterly trade winds from the Atlantic Ocean as well as the pronounced topographic characteristics during synoptically calm days (Garcia-Martino et al., 1996). The basin falls in the windward climatic region of 
Table 1. Physiographic and climatic characteristics of the Mameyes Basin and of the meteorological station, Bisley Tower (352 $\mathrm{m}$ a.s.1.): climate - mean diurnal, refers to the average variation of the variables throughout the day (numbers in parentheses refer to the minimum and maximum of the series); climate - mean annual, refers to the yearly average of the variables.

\begin{tabular}{ll}
\hline $\begin{array}{l}\text { Elevation } \\
\text { Slope }\end{array}$ & $\begin{array}{l}104.2 \text { to } 1046 \mathrm{~m} \text { a.s.l. } \\
0 \text { to } 80^{\circ}\left(30 \% \geq 25^{\circ}\right)\end{array}$ \\
Aspect & $\mathrm{N}(33 \%) \mathrm{S}(20 \%) \mathrm{E}(36 \%) \mathrm{W}(12 \%)$ \\
\hline Climate - mean diurnal & \\
\hline Temperature $\left({ }^{\circ} \mathrm{C}\right)$ & from 22 to $25(\min .17$ to max. 32) \\
Relative humidity $(\%)$ & from 80 to $92(\max .100)$ \\
Wind $\left(\mathrm{m} \mathrm{s}^{-1}\right)$ & from 1.1 to $1.8(\max .8 .6)$ \\
\hline Climate - mean annual & \\
\hline Mean Precipitation $\left(\mathrm{mm} \mathrm{yr}^{-1}\right)$ & 3300 \\
Wet fraction $(\%)$ & 17.4 \\
\hline
\end{tabular}

the island (see Table 1, Aspect), making it one of the wettest basins on the island. Because of the strong gradient in elevation, rainfall, cloudiness and temperature vary consistently throughout the basin. The mean annual precipitation (MAP) varies from approximately $3000 \mathrm{~mm}$, measured at an elevation of $352 \mathrm{~m}$ (Bisley Tower), to $5000 \mathrm{~mm}$ at higher elevations (Lepore et al., 2012). Table 1 reports some of the climatic characteristics of the basin.

In terms of vegetation, the Luquillo forest has been described as a mix of lower montane wet tropical, wet subtropical and rain forest (Ewel and Whitmore, 1973). The changes in the forest structure, composition and productivity denote three major forest types: the tabonuco forest (Dacryodes excelsa) in the wet subtropical and subtropical rain forest life zones, typically within the $150-600 \mathrm{~m}$ elevation range; the colorado forest (Cyrilla racemiflora) in the lower montane wet and rain forest life zones, within 600 and $900 \mathrm{~m}$; and the dwarf (cloud) forest, above $900 \mathrm{~m}$ (Waide et al., 1998) (see Fig. 2c). Another class present throughout the tabonuco and the colorado forests, is the palm forest (Prestoea montana), usually on steep and poorly drained sites or where climatic conditions (i.e., high winds) are undesirable for the other two species.

\section{Dataset/model input data}

We present here the parameter sets required by the tRIBSVEGGIE model.

\subsection{Meteorological data}

Hourly meteorological data are available at few locations within the LEF (http://www.sas.upenn.edu/lczo/). This study used the Bisley Tower meteorological data (lat. 18.31, long. 65.74, $352 \mathrm{~m}$ ) (see Fig. 2a and Table 1), which has been relatively continuous since 2002 with the exception of brief

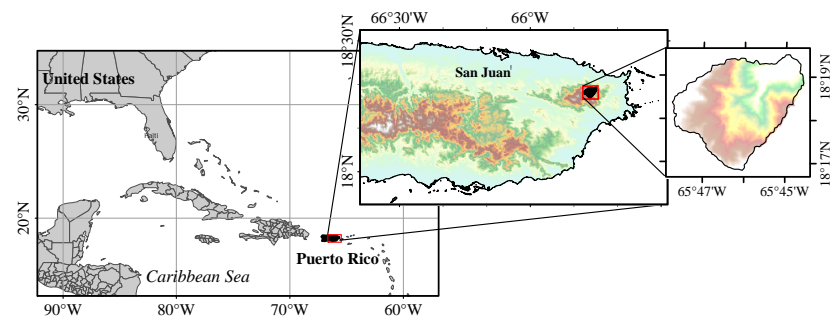

Fig. 1. Puerto Rico is an island of the Caribbean with a roughly rectangular shape. The Mameyes Basin is located in the northeast and on the most elevated areas of the island.

interruptions. Bisley Tower measures all the inputs needed by tRIBS-VEGGIE at an hourly resolution (wind speed and direction, air temperature, cloud cover, relative humidity, rainfall, incoming shortwave radiation) except for the atmospheric pressure, which was obtained from the NCDC weather station at San Juan airport (http://weather.noaa.gov/ weather/current/TJSJ.html). During the period from 7 July to 4 August 2008 only daily data were available at Bisley Tower. To fill this data gap, all the meteorological forcings, with the exception of precipitation and cloud cover, were replaced with average values observed for those days during other available years (2002-2007 and 2009-2010); the available daily rainfall data were disaggregated ad hoc into storms in order to be consistent with the measured soil moisture data (see Sect. 5). Table 1 reports the main characteristics of the station for the complete available time series (2002-2009).

\subsection{Surface data and parameters}

The basin was delineated from a $30 \mathrm{~m}$ DEM of the island (US Geological Survey (USGS) National Elevation Dataset (NED)). The hydrographic TIN method was used to derive the TIN mesh from the raster DEM (Vivoni et al., 2004). This method reduces the total number of elevation nodes, while preserving the distribution of topographic attributes as slope and curvatures, as well as hydrographic features.

The TIN is characterized by 2213 points and 1831 Voronoi cells, whose areas range from 212 to $63000 \mathrm{~m}^{2}$ (with average computational element area of $9000 \mathrm{~m}^{2}$ ) (Arnone, 2011). Figure 2a shows the TIN together with the elevation distribution for the basin; the blue lines illustrate the drainage network of the basin, whereas the red line delineates a subbasin used in the model confirmation (see Sect. 5). The soil data for the LEF were obtained from the USDA Forest Service's International Institute of Tropical Forestry of San Juan; the descriptions of the soil types are presented in USDA/NRCS (2002). The USDA defines 12 soil complexes within this basin; however, for this study these were further simplified to four soil types (Fig. 2b). The generalized soil properties database compiled by Rawls et al. (1982) is used here as a reference for most of the hydraulic properties of the soils; however, it underestimates the saturated hydraulic 


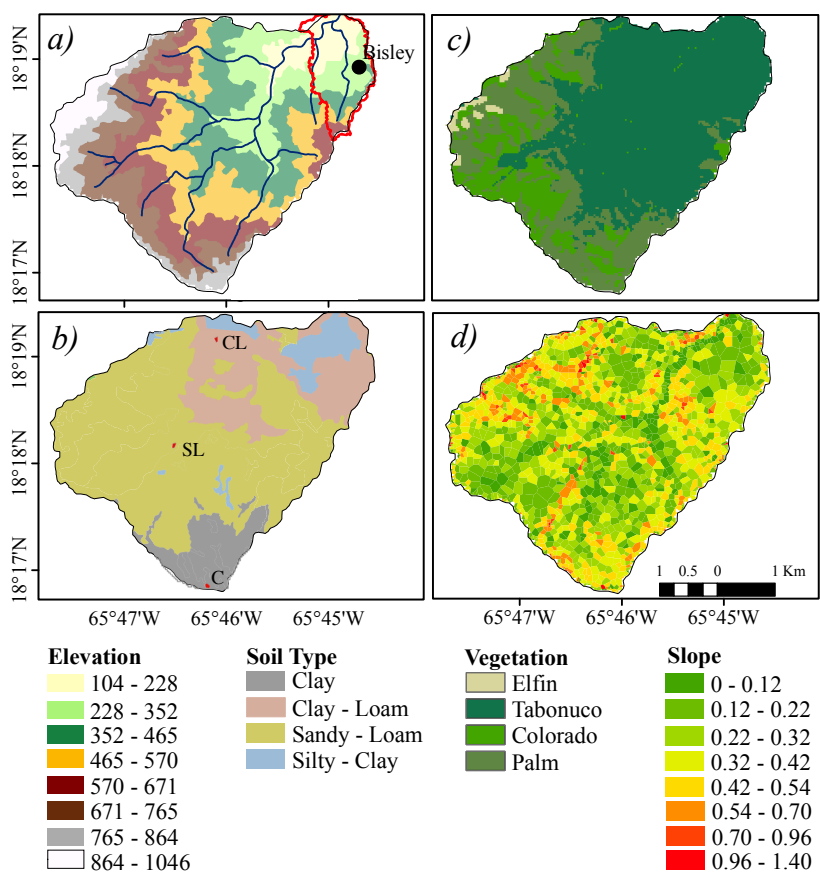

Fig. 2. Summary of the major characteristics of the Mameyes Basin: (a) the range of elevation and the drainage system, with the meteorological station, (b) the soil map and the three elements considered in Sect. 6 (in red polygons: C - clay element; CL - clay loam element; and SL - sandy loam element), (c) the vegetation map of the area with its features following closely the elevation range, and (d) the slope distribution of the basin.

conductivity when compared to other studies and measurements taken within the region of interest (Huffaker, 2002; Harden and Delmas Scruggs, 2003; Silver et al., 1994). This difference in saturated hydraulic conductivity, which are generally much higher than those listed in Rawls et al. (1982), has been attributed to the abundance of organic matter that increases soil drainage and infiltration volumes in wet montane and tropical environments (Harden and Delmas Scruggs, 2003; Knapp, 1978). Other specific characteristics of the soils present in the Mameyes Basin have been documented in previous studies: Harden and Delmas Scruggs (2003) observed a very high lateral subsurface flow parallel to the slope; Silver et al. (1994) measured a decrease of hydraulic conductivity with depth, coupled with an increase in bulk density values; and Simon et al. (1990) documented a clayrich horizon at $50 \mathrm{~cm}$ in dioritic soils. The soil bulk density measured within this basin covers a range from $600 \mathrm{~kg} \mathrm{~m}^{-3}$ for the first $30 \mathrm{~cm}$ and $1300 \mathrm{~kg} \mathrm{~m}^{-3}$ for deeper layers (Silver et al., 1994; Huffaker, 2002). The bedrock is located at a depth of $8 \mathrm{~m}$ or deeper (Simon et al., 1990) and is considered to not affect a shallow slope failure mechanism.

Because in TRIBS-VEGGIE we can allow for both variable unit weight of soil and saturated hydraulic conductivity with depth, we have considered various experimental setups based on one or a combination of the following three possible approaches: (1) allowing for a variable unit weight of soil and saturated hydraulic conductivity, which decreases with depth; (2) keeping both of them constant with depth; and (3) varying the anisotropy ratio $a_{\mathrm{r}}$ [-] (Ivanov et al., 2008a, b; Sivandran, 2012), a parameter in the model used to enhance the lateral redistribution of soil moisture, which has been reported to be significant in the Mameyes Basin (Harden and Delmas Scruggs, 2003).

tRIBS-VEGGIE defines the anisotropy ratio as the ratio of the saturated hydraulic conductivities in the directions parallel to the slope $K_{\mathrm{sp}}$ and normal to the slope $K_{\mathrm{sn}}$, and thus it is partially responsible of the lateral subsurface flux transfer. The lateral flux transfer is a topographically controlled process; for example, an isotropic soil (i.e., $a_{\mathrm{r}}=1$ ) implies same hydraulic conductivity both in the normal and parallel directions, but it does not imply that the same volume of water will flow in these two directions. Further details on the moisture flux model are given in Ivanov (2006).

Because the validation phase (Sect. 5) did not show a significant difference between the results of the runs with varying parameters (1) and those with constant ones (2), the landslide analysis presented in Sect. 6 has been based on approach (2), which represents not only the more parsimonious approach in terms of parameters but it also makes the interpretation of the results simpler.

With regard to the geotechnical parameters, Simon et al. (1990) and Lohnes and Demirel (1973) reported values for cohesive strength and friction angle for some of the geological units, and illustrated the expected high variability of these two quantities. The uncertainty associated with these parameters is large when we consider their spatial distribution across four soil types within the domain. For simplicity, this study will assume spatial homogenous values of cohesive strength $(3 \mathrm{kPa})$ and friction angle $\left(25^{\circ}\right)$ over the entire basin.

\subsection{Ecological data and parameters}

As previously mentioned, in this study, vegetation is assumed to be static, and thus the model does not simulate the temporal variability in leaf area index (LAI), net primary production (NPP), carbon pools, etc. of the forest. In preliminary analyses that allowed for dynamic vegetation, the resulting variability of these quantities over a short time period (less than $2 \mathrm{yr}$ ) was negligible; this was also supported by an analysis of satellite observations (MODIS Leaf Area Index) where there was little observed season dynamics in forest structure. However, in future, the dynamic vegetation component can be utilized to investigate the recovery of the forest after landslide events, and how the seasonal root dynamics may play a stabilizing role in shallow landslides. Figure $2 \mathrm{c}$ reports the actual vegetation map as in Helmer et al. (2002); however, our work assumes tabonuco forest only, because it is the predominant vegetation type of the basin 
and it is present where both the meteorological and the soil moisture measurements were taken. The tabonuco forest is modeled as broadleaf evergreen tropical (BET) class, with vegetation height of $20 \mathrm{~m}$ and a LAI of $6 \mathrm{~m}^{2} \mathrm{~m}^{-2}$ (Wang et al., 2003; Weaver and Murphy, 1990). The roots of the tabonuco forests are usually shallow, reaching about $40 \mathrm{~cm}$ in depth, and with the peculiarity of being connected with intraspecific root grafts (Basnet et al., 1993). In our application the root component has been modeled with a rectangular density function through a depth of $40 \mathrm{~cm}$, and their cohesive effect is included into the soil cohesion term. The remaining parameters used in the vegetation modeling have been extracted from the literature (Ivanov et al., 2008a, b; Schellekens, 2000; Wang et al., 2003; Weaver and Murphy, 1990).

\section{Model evaluation}

tRIBS-VEGGIE has been previously validated for semiarid areas showing the capabilities of the model to reproduce most of the hydrologically relevant fluxes and their very intricate feedback relationships with vegetation dynamics (Bisht, 2010; Ivanov et al., 2008a, b; Sivandran et al., 2008; Sivandran and Bras, 2012). The Mameyes Basin is very different from the previous validation sites, in terms of climate (tropical vs. semiarid), morphology (very steep vs. moderate steep), and vegetation type (BET vs. C4 or C3 grasses/shrubs).

For these reasons, we present here a confirmation of the hydrological model, based on soil moisture data. This confirmation has the intent to investigate the capabilities of tRIBSVEGGIE to correctly reproduce the soil moisture dynamics in tropical environment and to assess the role of some parameters for the application presented in Sect. 6. The data used for this model testing are nine soil moisture time series (Fig. 3a) measured at a $30 \mathrm{~cm}$ depth and hourly scale. In particular, the measurements were taken at three locations, all within a small area $500 \mathrm{~m}$ of Bisley Tower and each with three time-domain reflectometry (TDRs) Campbell Scientific Model CS616. These measurements are available from May to November of 2008 and were part of a broader research study carried out at the LEF focused on the climate change effects on humid tropical forests (T. Wood, personal communication, 2010). For the validation exercise we considered a smaller sub-basin within the Mameyes Basin, for faster simulation time and a finer mesh. The sub-basin, with 339 computational elements with an average area of $5000 \mathrm{~m}^{2}$, is shown in Fig. 2a delineated by the red line. The sub-basin covers two soil types of the Mameyes Basin, clay loam and silty clay, has a slope distribution limited within 0 and $30^{\circ}$ and aspects predominately $\mathrm{N}$ and NE facing.

The nine measurements (Fig. 3a) show a very high variability, both in terms of soil moisture average value and dynamics, even within measurements taken from the same plot.

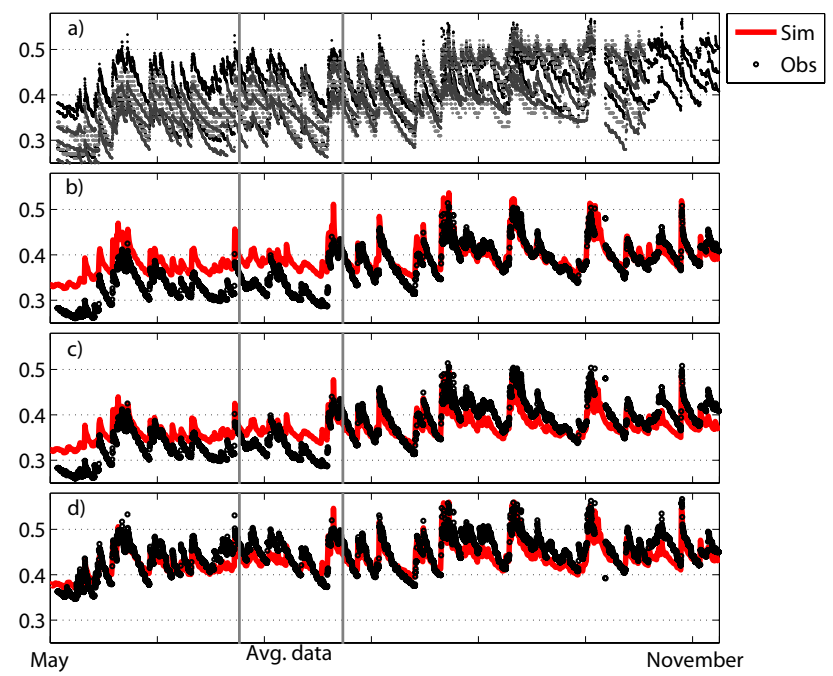

Fig. 3. Observed and modeled data for the period of May through November 2008. Panel (a) reports all the nine time series available; (b), (c) and (d) show three of the observed series and the corresponding simulated ones. The three simulations used the clay loam soil-type parameters, and were obtained with the highest value of $K_{\text {sat }}\left(50 \mathrm{~mm} \mathrm{~h}^{-1}\right)$ and different values of anisotropy ratio, equal to 100,150 and 200, respectively. The vertical lines delimit the time period when hourly data were not available and were reconstructed from average values (see text for details).

This variability has been explained by Jetten et al. (1993) and Harden and Delmas Scruggs (2003) as due to animal activity, vegetation and climate; in fact, the authors found that "the sample variance of infiltration rates for tropical rainforest soils to be so large that it was not possible to predict infiltration rate as a simple function of soil properties". For the above-mentioned reasons, particular attention has been paid to the role of the parameters $K_{\text {sat }}$ and $a_{\mathrm{r}}$, which proved to be the most important parameters to correctly reproduce the observed data.

As stated in the previous section, tRIBS-VEGGIE allows for the use of vertical profiles as input for $K_{\text {sat }}$ and $\gamma_{\mathrm{s}}$. In our model evaluation we carried out different runs by considering $K_{\text {sat }}$ and $\gamma_{\mathrm{s}}$ variable or constant with depth. For the depth variable case, $K_{\text {sat }}$ was assumed to decrease linearly with depth within the range of values reported in Table 2, column 4 , for the two considered soil types. The values used for the total unit weight of soil, $\gamma_{\mathrm{s}}$, were estimated from the bulk density values reported in Silver et al. (1994) and Huffaker (2002) variable with depth (Sect. 4). For the depth constant case, $K_{\text {sat }}$ was assumed equal to the minimum or the maximum value reported in Table 2, for each of the two considered soil types, while $\gamma_{\mathrm{s}}$ was set to $1700 \mathrm{~kg} \mathrm{~m}^{-3}$, corresponding to the maximum value of the $\gamma_{\mathrm{s}}$ profile used in the depth variable $\gamma_{\mathrm{s}}$ experiment.

Finally, each of these experimental setups was run for different anisotropy values, from 1 to 300 , with increments of 
Table 2. Hydraulic soil properties for the four soil types present in the Mameyes Basin. For clay loam and silty clay, column 4 reports the range of variability of $K_{\text {sat }}$ with depth used in testing the model (see Sect. 5); in bold are the hydraulic conductivity values actually used in the final experiments (Sect. 6).

\begin{tabular}{lrrlrr}
\hline Soil Type & $\begin{array}{r}\theta_{\mathrm{r}} \\
\mathrm{mm}^{3} \mathrm{~mm}^{-3}\end{array}$ & $\begin{array}{r}\theta_{\text {sat }} \\
\mathrm{mm}^{3} \mathrm{~mm}^{-3}\end{array}$ & $\begin{array}{l}K_{\text {sat }} \\
\mathrm{mm} \mathrm{h}^{-1}\end{array}$ & $\begin{array}{r}\psi_{\mathrm{b}} \\
\mathrm{mm}\end{array}$ & $\begin{array}{r}\lambda \\
-\end{array}$ \\
\hline Clay & 0.09 & 0.53 & 10 & -370 & 0.13 \\
Clay loam & 0.075 & 0.56 & $20-\mathbf{5 0}$ & -250 & 0.20 \\
Sandy loam & 0.041 & 0.55 & 50 & -150 & 0.32 \\
Silty clay & 0.051 & 0.55 & $20-\mathbf{3 0}$ & -340 & 0.13 \\
\hline
\end{tabular}

50. The values used for the others soil parameters (the residual and saturated soil moisture contents, $\theta_{\mathrm{r}}$ and $\theta_{\text {sat }}$; the air entry bubbling pressure, $\psi_{\mathrm{b}}$; and the pore-size distribution index, $\lambda$ ) are shown in Table 2 . The value of $\theta_{\text {sat }}$ corresponds to the upper value suggested by Rawls et al. (1982) for the corresponding soil type.

The choice of high values of anisotropy ratio is made to make the model able to describe the complex in situ water dynamics. Together with the slope, the anisotropy ratio is responsible for the subsurface lateral redistribution of soil moisture over the basin, which is assumed to be a gravitydriven flow. Increasing the values of anisotropy ratio enhances the ability of the model in reproducing the rapid lateral moisture exchange. A similar approach and such high values of anisotropy have been used by Ivanov et al. (2008b).

The model performance resulting from the different runs was judged based on the RMSE (root-mean-square error), calculated between soil moisture simulated at each run and measured at the nine locations.

No significant RMSE difference resulted from the use of depth variable or constant parameters. For the sake of simplicity, and for an easier interpretation of the results, here we present and describe the runs only for the case of constant values of $K_{\text {sat }}$ and $\gamma_{\mathrm{s}}$.

When comparing model output of two computational elements in the vicinity of Bisley Tower, each with an area of $6000 \mathrm{~m}^{2}$, the difference between the point scale measurements and output area scale must be kept in mind. However, tRIBS-VEGGIE does a very good job in reproducing the measured data; in particular, Fig. 3b, c and d illustrate the comparison of three of the nine soil measurements, black circles, with model results, red solid lines. The two grey vertical lines indicate the time period over which hourly data were not available and was reconstructed (see Sect. 4 for details). The simulated series shown in Fig. 3b, c and d use clay loam soil-type parameters and are obtained with the highest value of $K_{\text {sat }}\left(50 \mathrm{~mm} \mathrm{~h}^{-1}\right)$ and different values of anisotropy ratio, equal to 100,150 and 200 , respectively. The simulations reproduce well the three chosen observations, especially for the second part of the series. At some point it is not possible to distinguish between the observed and the modeled series; in particular, the maximum value of soil moisture and the wetting dynamic are well reproduced, and the overall dynamic is well captured even if, at times, the model seems not to be able to correctly reproduce the drying phase. Additionally, four (not shown here) of the nine simulated time series required again the highest value of $K_{\mathrm{sat}}$, for best results, while the remaining two (not shown here) performed best with the lower value of the range reported in Table 2. Based on these results, the values used for the final experiment (Sect. 6) are the highest values reported in Table 2, and highlighted in bold. The values of anisotropy ratio that were required by the nine simulations range from 50 to 200, proving the high variability of the parameter. For such reasons, a sensitivity analysis of FS to $a_{\mathrm{r}}$ is carried out in the final experiment by choosing even higher values of anisotropy ratio in order to stress the model and bring the basin to very different conditions in terms of soil moisture spatial distribution (see Sect. 6).

The testing cannot be extended to other soil types present in the basin because of the lack of soil moisture measurements. However, given that the hydraulic parameters based on Rawls et al. (1982) used in the validation provided good results, the rest of this work will utilize the same parameters' dataset to represent and simulate other soil types in the remaining parts of the basin.

\section{Slope stability analysis}

The previous section showed that both anisotropy and hydraulic conductivity were the most important parameters and required careful selection in order to reproduce the observed data. The model captured most of the observed soil moisture dynamics, but the high variability of soil measurements suggested that it is not, at present, possible to identify a unique value of anisotropy ratio, even within the same small area close to Bisley Tower, where the measurements were taken.

This section will focus on the sensitivity of the timing and depth of failures obtained from the slope stability model to the parameterization of anisotropy coefficient. As reported in Sect. 4, spatial homogenous values of cohesive strength and friction angle were assumed over the entire basin. This simplifying assumption does not affect the sense of the analysis described in this section, which aims to investigate the impact of the above-mentioned hydrological properties on landslidemodeling results.

In order to explore the sensitivity to anisotropy ratio of the slope stability model, three anisotropy coefficients $-a_{\mathrm{r} 1}$, $a_{\mathrm{r} 2}$ and $a_{\mathrm{r} 3}-$ equal to 1 (isotropic soil), 300 and 500, respectively, were simulated. As stated in the previous section, the high values of anisotropy coefficients are used to characterize the basin with very different patterns of soil moisture, and thus to evaluate how a very rapid lateral moisture exchange, which is very common in the basin area, may affect the landslide triggering within the area. The same meteorological, ecological and hydrological data used for the 
validation was used. The initial conditions of each experiment were obtained through a spin-up initialization time of 12 months, with the meteorological forcing of year 2007, during which the model adjusts itself and moves from the initial conditions to an equilibrium state (Yang et al., 1995; Noto et al., 2008). Results are analyzed both at element scale, to evaluate the behavior of slope stability over the whole column of soil, and spatially, to evaluate the distribution of unstable elements.

The vertical computational mesh is considered as a homogeneous soil deposit of $2000 \mathrm{~mm}$, with failure surfaces corresponding depths where the FS approaches 1.

\subsection{Landslide analysis at element scale}

Model results are shown for three selected elements falling within three different soil types: a clay element $(\mathrm{C})$ with a slope of $56^{\circ}(0.98 \mathrm{rad})$, clay loam (CL) with a slope of $52^{\circ}$ $(0.90 \mathrm{rad})$ and sandy loam (SL) with a slope of $47^{\circ}(0.82 \mathrm{rad})$ (small red labeled polygons in Fig. 2b). The CL and C elements are located upslope, while the SL element is closer to the river network; these elements have been selected in order to have the most representative results in terms of slope condition; other elements throughout the basin have been analyzed, and gave similar results.

Temporal dynamics of the soil moisture profile and the FS are analyzed by focusing the discussion on a time window of $48 \mathrm{~h}$ encompassing the most severe event of the simulation period. This period corresponds to a rainfall event recorded between the 27 and 28 April 2008 with a peak rainfall intensity of $100 \mathrm{~mm} \mathrm{~h}^{-1}$.

Figure 4 shows results relative to the three anisotropy values used for the simulation for the CL element. The corresponding infiltration dynamics and soil moisture pattern are reported on the left panels. The initial wedge along the profile depicts homogeneous soil water content before the rainfall event. Rainfall peaks at $t=t_{\mathrm{a}}$ and at $t=t_{\mathrm{b}}$ produce an increase of water content in surface layers (red wedge) up to saturated values, which then propagates vertically through the profile. Fully saturated conditions are achieved only for isotropic soil, $a_{\mathrm{r} 1}$ of 1 , in the first $300 \mathrm{~mm}$ at time $t_{\mathrm{c}}$. In fact, with $a_{\mathrm{r} 1}=1$, moisture is retained in the soil column for the longest time, relative to simulations with other anisotropy ratios. Increasing the anisotropy alters the redistribution of soil moisture, and consequently water leaves the column faster, with a shallower depth of infiltration; the two rainfall events impact only the superficial layers to a depth of about $1250 \mathrm{~mm}$ for $a_{\mathrm{r} 2}$ and $1000 \mathrm{~mm}$ for $a_{\mathrm{r} 3}$.

Right panels of Fig. 4 illustrate instantaneous FS vertical profiles at selected time periods $\left(t_{\mathrm{a}}, t_{\mathrm{b}}, t_{\mathrm{c}}, t_{\mathrm{d}}\right)$ for the three anisotropy cases. Abrupt changes in the shape of the curves denote a sudden change in soil moisture. When soil moisture is constant, the FS simply decreases with depth according to Eq. (3), whereas with variable moisture both depth and moisture content play an important role. In particular,

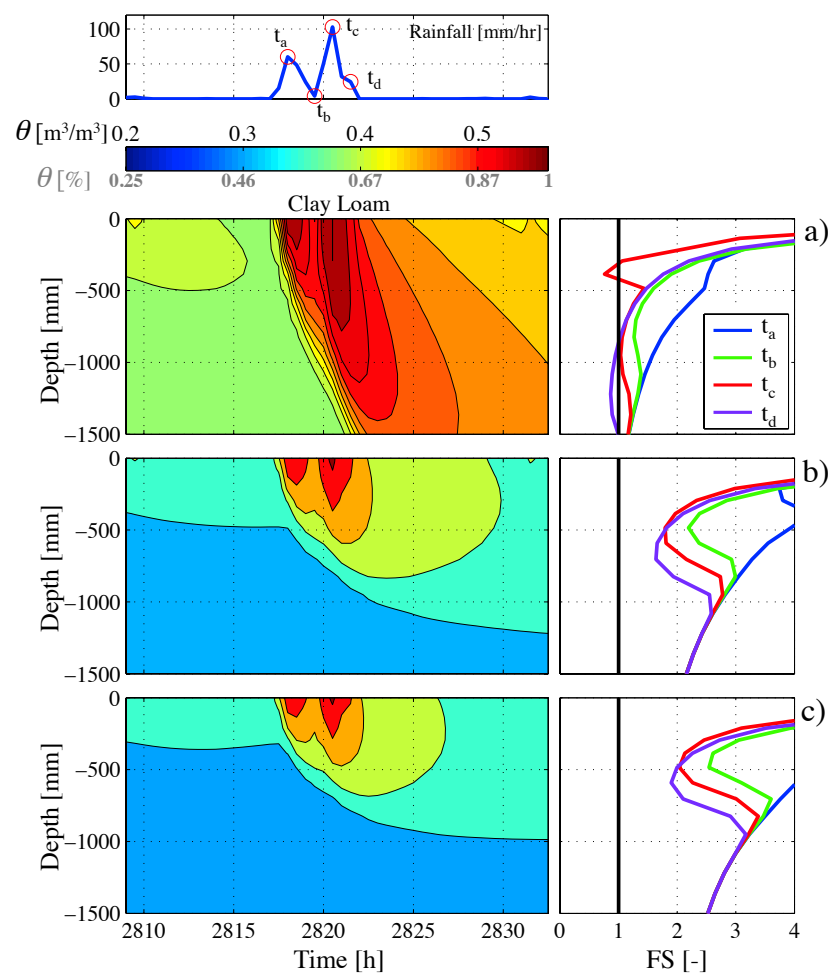

Fig. 4. Temporal evolution at element scale of soil moisture and FS dynamics for a clay loam element with slope $52^{\circ}$, for anisotropy values equal to 1 (a), 300 (b) and 500 (c).

Fig. 4a, corresponding to isotropic soil, shows that the selected element fails at time $t_{\mathrm{c}}$ (red line) and depth of about $400 \mathrm{~mm}$, when the soil is fully saturated. At time $t_{\mathrm{c}}$, critical FS values $(<1.3)$ are also reached at a depth of about $1000 \mathrm{~mm}$. At time $t_{\mathrm{d}}$ (purple line), the soil column is not fully saturated; however the combination of soil weight and moisture level makes this condition unstable deeper in the soil column ( $\mathrm{FS}<1)$.

In contrast, for $a_{\mathrm{r} 2}$ or $a_{\mathrm{r} 3}$ the element never reaches a critical value and FS values increase with anisotropy ratio. Increasing the anisotropy ratio involves a higher rate of lateral fluxes, which results in more lateral redistribution of water, and in this case lower values of soil moisture in upstream locations, which impacts FS. However, it is still possible to see the influence of the wetting front in the column in the superficial layers, where lower FS values are recorded after the rainfall peak, at $t_{\mathrm{c}}$ and $t_{\mathrm{d}}$.

Figure 5 shows the profile results for the SL element as a function of the same three anisotropy values, $a_{\mathrm{r} 1}, a_{\mathrm{r} 2}$ and $a_{\mathrm{r} 3}$. As in the previous case, fully saturated conditions are achieved for $a_{\mathrm{r} 1}$ at time $t_{\mathrm{c}}$ (Fig. 5a, left panel), which at a depth of $300 \mathrm{~mm}$ shows a drop in FS to values only slightly greater than 1 (Fig. 5a right panel) and a second decrease of FS values from $600 \mathrm{~mm}$ and deeper. The feature at $300 \mathrm{~mm}$ of depth is mainly due to the instantaneous peak of rainfall at $t_{\mathrm{c}}$, whereas the deeper FS feature is due to the previous 
rainfall amounts propagated to greater depths. In fact, due to the higher hydraulic conductivity and gentler slope of the element, the wetting front infiltrates faster than in the CL case, resulting in a narrow wedge, and values of soil moisture close to saturation down to a depth of $850 \mathrm{~mm}$, where the element fails two hours after the first rainfall peak $\left(t_{\mathrm{c}}\right)$. Moving from $a_{\mathrm{r} 1}$ to $a_{\mathrm{r} 2}$ and $a_{\mathrm{r} 3}$, propagation of the infiltration wedge is limited to the more superficial layers (Fig. 5b and $\mathrm{c}$ left panel) and FS is always greater than 1, and thus the element is always stable.

Figure 6 illustrates the results for the selected clay element (C). Water content dynamics for $a_{\mathrm{r} 1}$ are significantly different from the previous cases. Infiltration rate is lower because of the lower value of hydraulic conductivity and the great volumes of surface runoff; however clay retains more water, and thus the initial condition is wetter than the other two cases. The increase of water content due to rainfall contribution at times $t_{\mathrm{a}}$ and $t_{\mathrm{b}}$ up to values close to the saturated condition is limited to the surface layers down to a depth of about $250 \mathrm{~mm}$. In term of stability (right panel), the most severe value of FS is achieved for $a_{\mathrm{r} 1}$ at a depth of about $900 \mathrm{~mm}$ two hours after the event $\left(t_{\mathrm{d}}\right)$, but critical FS values (less than 1.3) are present down to a depth of $1500 \mathrm{~mm}$. Increasing the anisotropy ratio (second and third row) results in a slower percolation rate in the normal direction, and limits the vertical propagation of the wetting front (left panels). With regard to slope stability (right panels), FS values fluctuate in response to the wetting front but never fall below 1.5, and no failure occurs within the $2 \mathrm{~m}$ of soil.

\subsection{Landslide analysis at basin scale}

In this section the links between soil moisture patterns over the whole basin and the FS values are evaluated, while changing the anisotropy coefficient. Model outputs return spatially distributed results at selected time periods and selected depth, providing us the distribution of instantaneous values of a selected variable of interest (in this case, FS and soil moisture). The value of the FS at each element is taken either as the minimum value within the soil column or as the first value, from top to bottom, resulting in a failure. It is important to mention that post-event dynamics are not simulated here. Whenever an element fails, FS is computed again at the next time step based on the updated soil moisture but no change in topography.

Figures 7 and 8 show the results obtained for $a_{\mathrm{r} 1}$ and $a_{\mathrm{r} 2}$. Similar analyses, not reported here, have been carried out for $a_{\mathrm{r} 3}$. They depict the spatial distribution of soil moisture at depths of about 485 (top row) and $950 \mathrm{~mm}$ (middle row), and the FS spatial distribution with the corresponding histogram of absolute frequency of failures at different depths (bottom rows), for four time steps (from left to right, $t_{\mathrm{a}}$ to $t_{\mathrm{d}}$ )

Figure $7 \mathrm{a}\left(a_{\mathrm{r} 1}\right)$ shows that soil moisture pattern is strongly dependent on soil-type distribution over the basin, and values of soil moisture are quasi homogenously distributed within

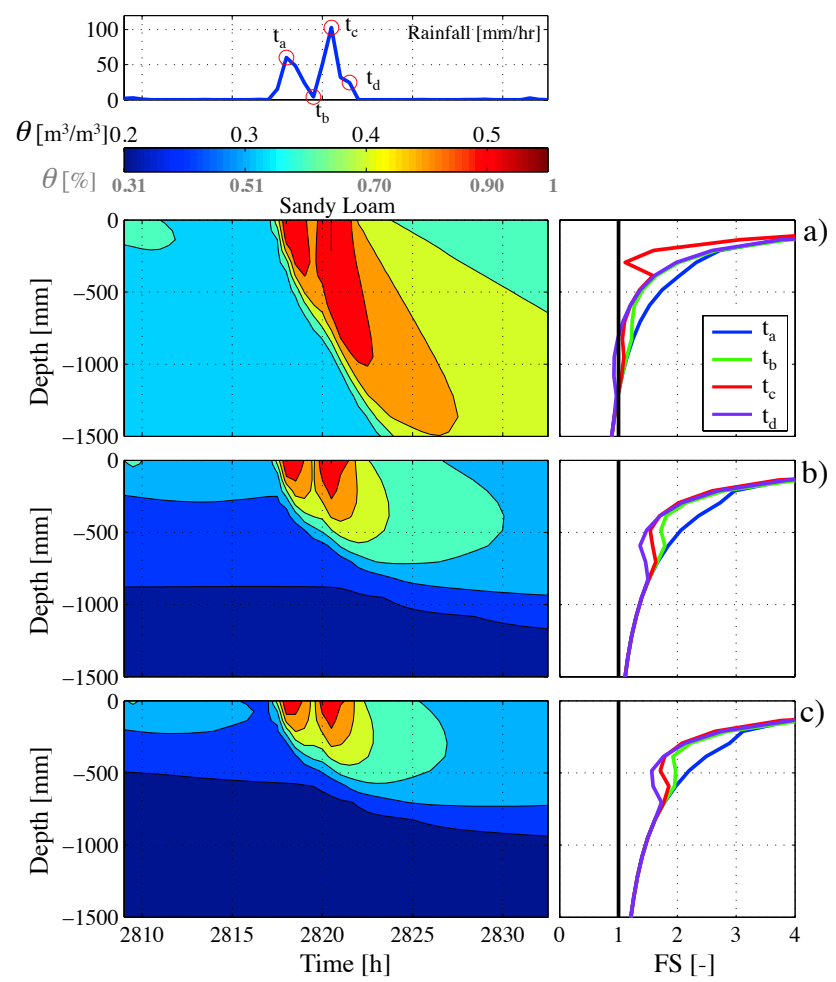

Fig. 5. Temporal evolution at element scale of soil moisture and FS dynamics for a sandy loam element with slope $47^{\circ}$, for anisotropy values equal to 1 (a), 300 (b) and 500 (c).

each type $\left(t_{\mathrm{a}}\right)$. The entire soil clay area (bottom corner of the basin map), because of its properties, shows higher values of soil moisture at both times $t_{\mathrm{a}}$ and $t_{\mathrm{b}}$; the variation through time is small, and it rarely reaches full saturation due to the slow dynamics of infiltration. The deeper we move, the longer the lag in the response of the basin to rainfall forcing (Fig. 7b). The resulting FS spatial distributions are shown in Fig. 7c: black elements denote areas where FS $\leq 1$; from red to white, FS values gradually increase up to values greater than 5. Since the geotechnical parameters $\left(c^{\prime}\right.$ and $\left.\varphi\right)$ are assumed homogeneous over the whole basin, the clay zone is expected to be more stable during our simulations because of the following: (a) in this area soil rarely achieves the fully saturated conditions and, as a consequence, (b) the matric suction effect plays its stabilizing role; this effect is particularly strong for a clay due to its fine texture. Together with clay elements, flat areas also result in larger FS values. In contrast, the steepest elements commonly fail. The number of failing Voronoi cells for each depth (and up to a depth of $2 \mathrm{~m}$ ) is shown in the absolute frequency histogram reported at the top of each map (Fig. 7c). At $t=t_{\mathrm{a}}$ and $t=t_{\mathrm{b}}$ around 121 Voronoi cells fail, all at depths larger than $1000 \mathrm{~mm}$; at the time of the highest rainfall peak $\left(t=t_{\mathrm{c}}\right)$, the number of failing elements rises to 278 , mainly at depths between $385 \mathrm{~mm}$, with 79 failing elements, and $485 \mathrm{~mm}$, with 

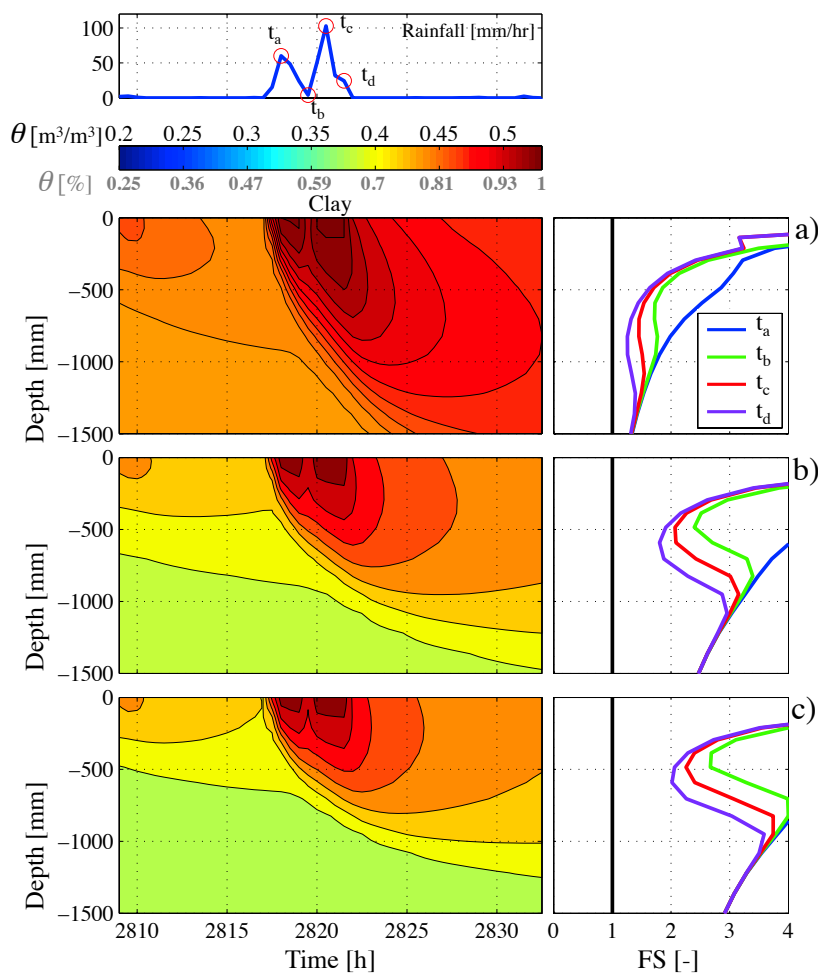

Fig. 6. Temporal evolution at element scale of soil moisture and FS dynamics for a clay element with slope $56^{\circ}$, for anisotropy values equal to 1 (a), 300 (b) and 500 (c).

81 failing elements, due to the high water content present in shallow layers and mostly distributed in clay loam and sandy loam. As we move from $t=t_{\mathrm{c}}$ to $t=t_{\mathrm{d}}$, the number of failing elements drops down to around 145, but they now occur at larger depths, between 700 and $1100 \mathrm{~mm}$.

Results for $a_{\mathrm{r} 2}$ are shown in Fig. 8 for the same four time steps. The soil moisture pattern at time $t_{\mathrm{a}}$ (Fig. 8a, left panel) is similar to Fig. 7. At the next time steps (Fig. 8a, center and right panel), the effect of soil-type distribution on the soil moisture pattern is less evident due to the higher anisotropy that is redistributing water laterally. Moving from depth $450 \mathrm{~mm}$ to depth $950 \mathrm{~mm}$ (Fig. 8b), the soil moisture pattern is more influenced by the topography (slope distribution), which determines the lateral flow directions; in fact, the drainage of the steepest areas is larger than in the previous case, and thus the soil moisture is locally lower. Slope instability occurs only in a few elements at depths deeper than $1500 \mathrm{~mm}$, with a frequency distribution almost invariant in time (Fig. 8c), suggesting that the failing elements are always unstable for these set of parameters.

\subsection{Analysis of failing elements}

Further analyses between failing elements and topographical properties are presented in this section, where we look at the relationship between failure depth, number of failing elements, slope and soil moisture (SM). Figures 9 and 10 show the distribution in frequency of failure depths (column 1) and scatterplots of slope vs. depth (column 2), and SM vs. depth (column 3 ) of the failing elements, for the anisotropy ratio values $a_{\mathrm{r} 1}$ and $a_{\mathrm{r} 2}$, respectively. The analysis is repeated for time $t_{\mathrm{b}}, t_{\mathrm{c}}$ and $t_{\mathrm{d}}$, and presented in the three rows.

The two red lines designate the limits of the region of all possible instability cases; particularly, for Fig. 9, column 2, the upper red line describes the worst conditions obtained from Eq. (3) at a fully saturated state of the most permeable soil (sandy loam, which is also the dominant soil type in the domain), and the lower line is obtained from Eq. (3) at unsaturated conditions for the minimum value of soil moisture at which a failure occurs $(0.29)$. At time $t_{\mathrm{b}}$ for column 2 , the distribution of the circles within the defined region hints at a curve that can be described by Eq. (3) at constant soil moisture value. It follows that over the basin, failures occur at a specific soil moisture value, i.e., for same values of the effective saturation, and, according to Eq. (3), shallower failures occur at steeper slopes. Failure at $1000 \mathrm{~mm}$ occurs wherever the slope is greater than a value of about $46^{\circ}(\sim 0.80 \mathrm{rad})$, except for a few steeper elements $\left(>52^{\circ}, \sim 0.90 \mathrm{rad}\right)$ that fail at 1800 and $2000 \mathrm{~mm}$. Gentler slopes fail at depths between 1200 and $2000 \mathrm{~mm}$. At the time corresponding to the rainfall peak $\left(t_{\mathrm{c}}\right)$, most of the failures occur at shallower depths and follow the upper red line, meaning that the soil is fully saturated; other elements also fail at deeper depths and unsaturated conditions. For the last time step, $t_{\mathrm{d}}$, depths increase again, as the wetting front moves deeper.

Column 3 describes the relation between depths and soil moisture. The region of possible unstable states was defined from Eq. (3) at fixed slope values by considering the steepest slope $\left(63^{\circ}, \sim 1.1 \mathrm{rad}\right.$, upper red line) and two gentler slopes $\left(35^{\circ}, \sim 0.6 \mathrm{rad}\right.$, lower solid line; $23^{\circ}, \sim 0.4 \mathrm{rad}$, dashed line). Failure at steep slopes can occur for any value of moisture; the wetter the condition, the shallower the failure. A slope equal to $35^{\circ}$ represents the minimum slope at which most of the elements fail, as seen in column 2 . At time $t_{\mathrm{b}}$, most of the failures occur at a soil moisture of $\sim 0.30$, while at time $t_{\mathrm{c}}$ and $t_{\mathrm{d}}$, when the wetting front has reached deeper layers, failures occurs at conditions close to the saturation and at saturation ( 0.55 or 0.56 , depending on the soil type).

With anisotropy ratio $a_{\mathrm{r} 2}$, the soil moisture values of failing elements are more spread out and lower in magnitude, as presented in Fig. 10. As clearly shown by column 2 and 3, failures occur now for a wider and lower range of soil moisture values, corresponding to unsaturated conditions; consequently, circles are not distributed along a curve. In fact, despite that the failing elements mainly fall within the same soil type (see Fig. 8c), the soil moisture values at which failures occur are different, and thus each circle belongs to different theoretical curves at fixed effective saturation. Moreover, the frequency distribution highlights that failures occur at higher depths than those found in Fig. 9, since the weight of soil is more important in triggering failure than the soil moisture state. 


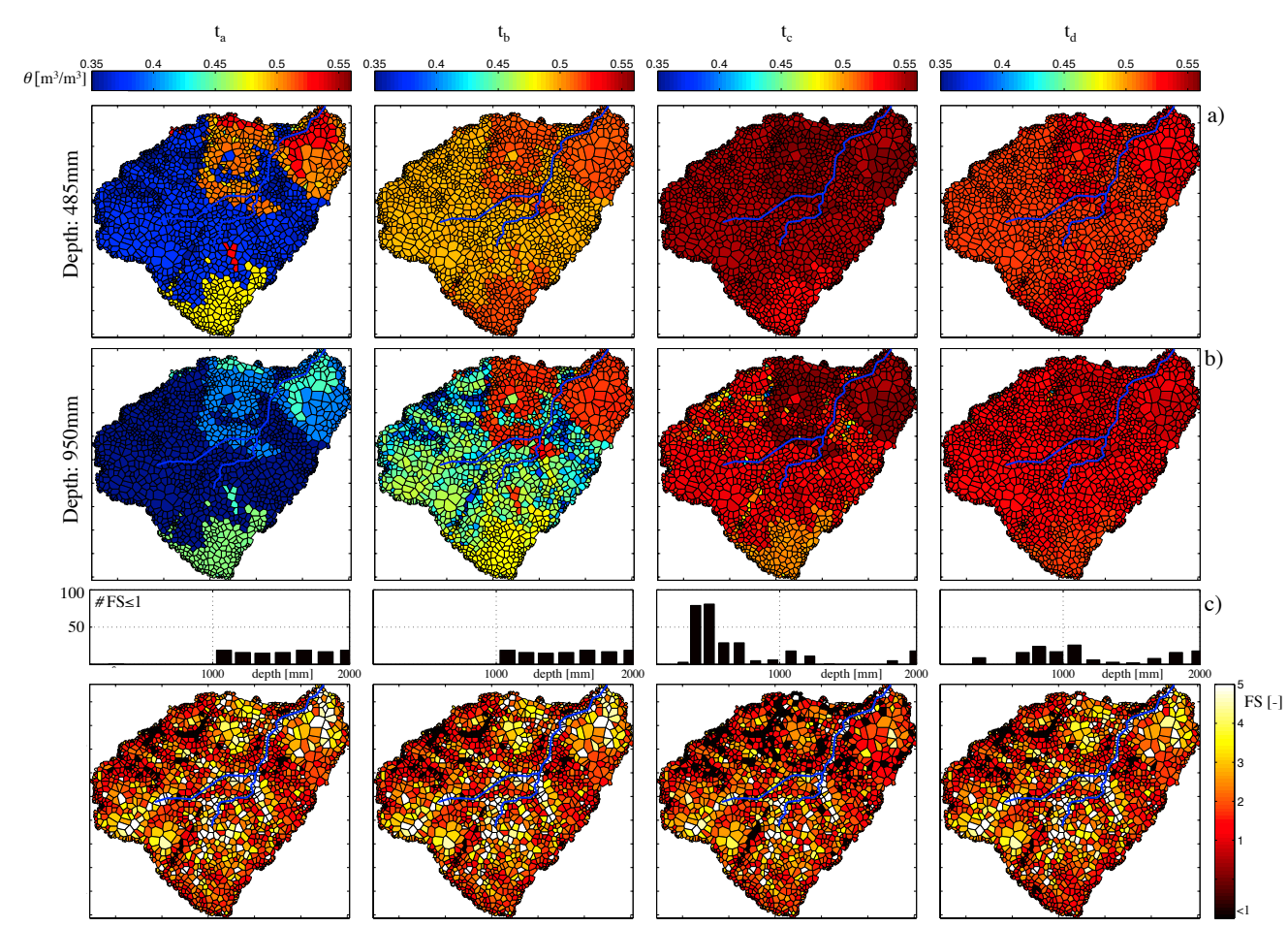

Fig. 7. Spatial distribution at selected time steps (from left to right: $t_{\mathrm{a}}, t_{\mathrm{b}}, t_{\mathrm{c}}$ and $t_{\mathrm{d}}$ ) for anisotropy equal to 1 : soil moisture at depths $485 \mathrm{~mm}$ (a) and $950 \mathrm{~mm}$ (b), and FS distribution obtained either as the minimum value along the vertical profile or as the first depth where FS $\leq 1$ (c).
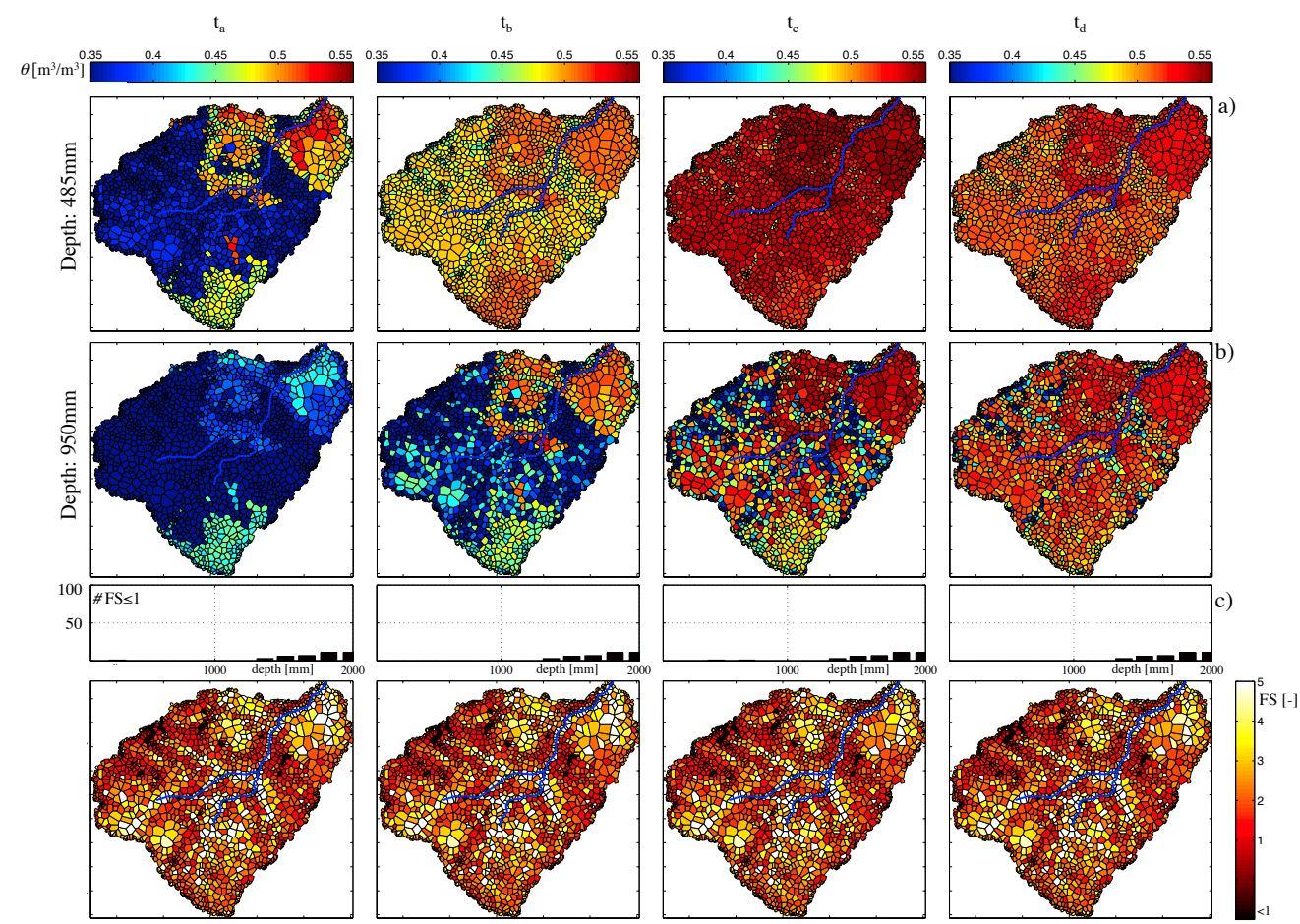

Fig. 8. Spatial distribution at selected time steps (from left to right: $t_{\mathrm{a}}, t_{\mathrm{b}}, t_{\mathrm{c}}$ and $t_{\mathrm{d}}$ ) for anisotropy equal to 300 : soil moisture at depths $485 \mathrm{~mm}$ (a) and $950 \mathrm{~mm}$ (b), and FS distribution obtained either as the minimum value along the vertical profile, for FS always larger than 1 , or as the first depth where FS $\leq 1$ (c). 


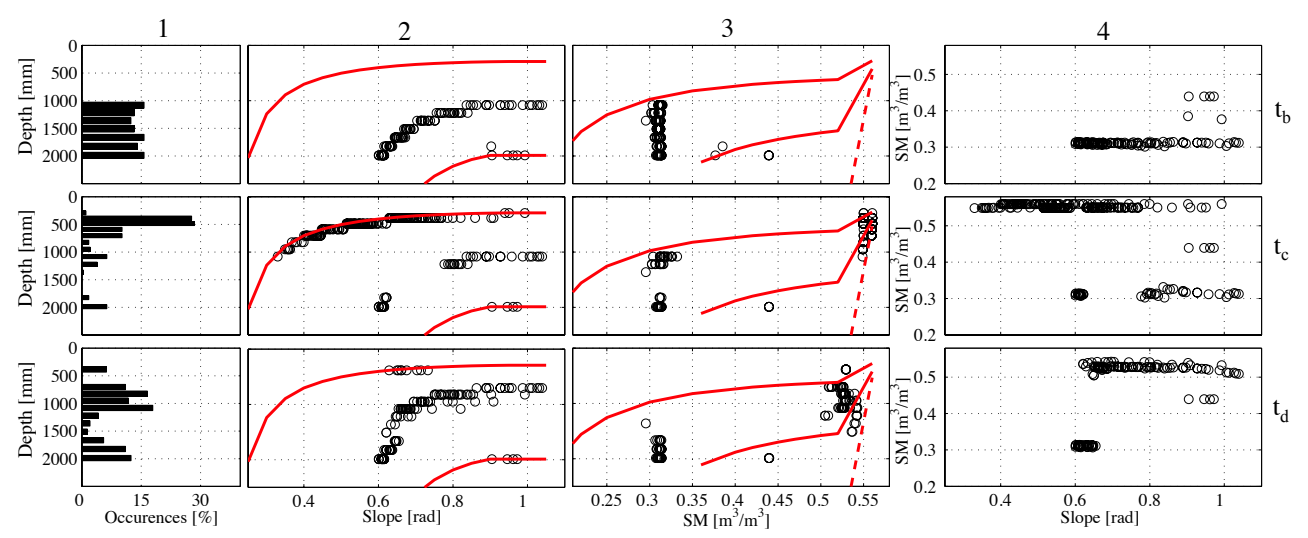

Fig. 9. Frequency distribution of failure depths (column 1), scatterplots of slope vs. depth (column 2) and SM vs. depth (column 3) for all failing elements at time steps increasing with rows $\left(t_{\mathrm{b}}, t_{\mathrm{c}}, t_{\mathrm{d}}\right)$ with anisotropy equal to 1 . The red lines designate the limits of the region of all possible instability cases. For column 2, the upper red line describes the worst conditions obtained from Eq. (3) at a fully saturated state of the most permeable soil (sandy loam), and the lower line is obtained from Eq. (3) at unsaturated conditions for the minimum value of soil moisture at which a failure occurs $\left(0.29 \mathrm{~m}^{3} \mathrm{~m}^{-3}\right)$; for column 3, the red lines are obtained from Eq. (3) at fixed slope values by considering the steepest slope $\left(63^{\circ}, \sim 1.1 \mathrm{rad}\right.$, upper red line) and two gentler slopes $\left(35^{\circ}, \sim 0.6 \mathrm{rad}\right.$, lower solid line; $23^{\circ}, \sim 0.4 \mathrm{rad}$, dashed line $)$.

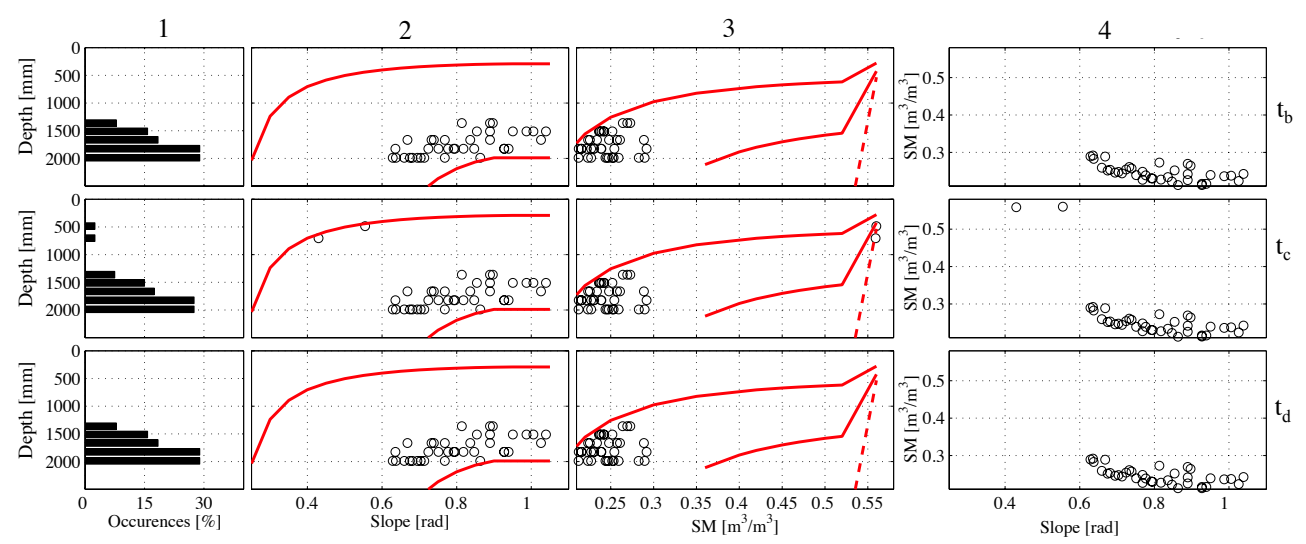

Fig. 10. Frequency distribution of failure depths (column 1), scatterplots of slope vs. depth (column 2) and SM vs. depth (column 3 ) for all failing elements at time steps increasing with rows $\left(t_{\mathrm{b}}, t_{\mathrm{c}}, t_{\mathrm{d}}\right)$ with anisotropy equal to 300 . The red lines designate the limits of the region of all possible instability cases. For column 2, the upper red line describes the worst conditions obtained from Eq. (3) at a fully saturated state of the most permeable soil (sandy loam), and the lower line is obtained from Eq. (3) at unsaturated conditions for the minimum value of soil moisture at which a failure occurs $\left(0.29 \mathrm{~m}^{3} \mathrm{~m}^{-3}\right)$; for column 3, the red lines are obtained from Eq. (3) at fixed slope values by considering the steepest slope $\left(63^{\circ}, \sim 1.1 \mathrm{rad}\right.$, upper red line) and two gentler slopes $\left(35^{\circ}, \sim 0.6 \mathrm{rad}\right.$, lower solid line; $23^{\circ}, \sim 0.4 \mathrm{rad}$, dashed line).

\subsection{Discussion}

The initiation of shallow landslides is highly controlled by hydrological processes that govern the amount of water contained in the soils; however the role of hydrology is not always evident in existing coupled hydrological-stability models. The results of this study provide an in-depth investigation of how soil moisture affects the slope stability in relation to topography (slope distribution) and soil-type characteristics. The impact of the most important hydrological parameters (soil properties, hydraulic conductivity and anisotropy coefficient) is also elucidated. Particularly, the analysis highlighted the following findings:
- In the more permeable soil, initiation of instability mostly occurs at the more superficial layers, where a full saturation condition is most often achieved during precipitation events.

- In the less permeable soil, the effects of the rainfall event on slope stability are delayed.

- At equal degree of saturation, i.e., relative unsaturated soil moisture content, the stabilizing effect of matric suction on slope stability is greater in finer soils, where $\psi$ values are higher. 
- Higher values of anisotropy cause fewer pixels to cross the critical FS value because of a faster lateral redistribution of water that result in dryer deeper layers.

- Higher values of anisotropy lead to delayed effects of instability conditions on both permeable and impermeable soils.

- Increasing the anisotropy in clayey soils leads to more significant changes of the FS than a permeable soil, especially in deeper depths.

- Increasing the anisotropy showed that critical FS values can be reached over a greater range of soil moisture values, and thus also over unsaturated conditions.

- Finally, when anisotropy is high, failure occurs at deeper soil layers.

The results of such a process-driven methodology highlight the importance of a correct parameterization of hydrological processes, not only for hydraulic conductivity and parameters of soil retention curve but also in terms of anisotropy ratio required to simulate in an appropriate way the processes of the lateral redistribution of soil moisture.

\section{Conclusions}

This study presents the development and analysis of a rainfall-triggered landslide-modeling tool that includes both saturated and unsaturated states and can monitor the FS dynamics at high spatial and temporal resolutions.

The modeling of landslide susceptibility is highly dependent on the parameterization of hydrologic characteristics, such as soil moisture dynamics, and on the knowledge of the geotechnical properties of a specific area. In particular, this model is capable of capturing dynamics of soil moisture, and it has been shown to perform well in reproducing observations in both arid and tropical climates. However, a detailed knowledge of some key geotechnical parameters is still very difficult. This study investigated the response of the landslide model to different ranges of a key hydrological parameter such as the anisotropy ratio, which showed the importance of (1) the correct modeling of the lateral moisture redistribution and (2) the inclusion of the unsaturated processes in the definition of the instability of a hillslope. In particular, for the analyzed area, high values of anisotropy ratio improves the capability of the model to reproduce the observed soil moisture dynamics and leads to a more "realistic" spatial distributions of unstable areas.

Some significant assumptions were made in this study, and the lack of information on distributed geotechnical parameters and on the timing of historical landslide data have not facilitated a strict confirmation of the landslide model component. Nevertheless, the scope of the study was not to define a real-time forecasting of slope failure for the area, but rather to demonstrate the potential capabilities of the model and evaluate the effects of hydrological properties on slope stability. In fact, the complex yet flexible framework of this model makes its use in other areas simple. The detailed soil moisture description, based on the numerical solution to the Richards' equation, allows for computing the FS locally with no need to make a priori assumptions on the failure surface depth. Moreover, the extended failure criterion formulation, makes it suitable to applications where failures can occur both in saturated and unsaturated conditions.

Many more open questions could be investigated within this framework, such as analysis of the effect of a small localized disruption on a larger area; the effects on slope stability of changes in the rainfall pattern and intensities due to climate change, the effects of deforestation or reforestation on slope stability or the effect of resolution in the topography description. Future extensions of the work will focus on including vegetation dynamics in order to show the importance of vegetation in slope stability both through its role in moisture fluxes partitioning and through the stabilizing effects of the root biomass.

The detailed descriptive capability of the model, with the FS evaluated at each time step and at various soil depths, together with the flexibility of the hydrology model in describing soil moisture dynamics in a variety of settings, make the presented work a promising tool for landslides assessment.

Acknowledgements. The work has been funded by the $\mathrm{Na}$ tional Aeronautics and Space Administration under NASA project NNX07AD29G, Predicting Landslides Using Measurements of Precipitation from Space, and by the Regional Sicilian Government (Italy), "Linea di intervento 4.1.1.1 - POR FESR Sicilia 20072013" under project SESAMO - SistEma informativo integrato per l'acquisizione, geStione e condivisione di dati AMbientali per il supportO alle decisioni.

We are thankful to Matthew C. Larsen, Associate Director, Climate and Land Use Change, US Geological Survey, for providing landslide data. We greatly appreciate the helpful assistance and data provided by the late Frederick N. Scatena of the Department of Earth and Environmental Science, University of Pennsylvania; his knowledge of the Luquillo forest was key to the development of this work. We want to thank Miguel Leon, LQLTER, and the International Institute of Tropical Forestry of the US Department of Agriculture Forest Service, Rio Piedras, Puerto Rico. We also want to thank the reviewers for their help in improving the manuscript.

Edited by: R. Greco

\section{References}

Arnone, E.: An Integrated System for the Analysis of RainfallTriggered Landslides, Universita' degli Studi di Palermo, Palermo, 2011.

Arnone, E., Noto, L. V., Lepore, C., and Bras, R. L.: Physicallybased and distributed approach to analyze rainfall-triggered landslides at watershed scale, Geomorphology, 133, 121-131, 2011. 
Bao, C. G., Gong, B. W., and Zhan, L. T.: Properties of unsaturated soils and slope stability of expansive soils, Proceedings of the Second International Conference on Unsaturated Soils - UNSAT98, Beijing, China, 71-98, 1998.

Basnet, K., Scatena, F. N., Likens, G. E., and Lugo, A. E.: Ecological consequences of root frapthing in tabonuco (Dacryodes excelsa) trees in the Luquillo Experimental Forest, Puerto Rico, Biotropica, 25, 28-35, 1993.

Baum, R. L., Savage, W. Z., and Godt, J. W.: TRIGR-a Fortran program for transient rainfall infiltration and grid-based regional slope-stability analysis, US Geological Survey Open File Report 2008-1159, 75 pp., 2008.

Bishop, A. W.: The use of the slip circle in the stability analysis of slopes, Geotechnique, 5, 7-17, 1955.

Bisht, G.: Satellite-based estimates of net radiation and modeling the role of topography and vegetation on inter-annual hydroclimatology, M.I.T., 2010.

Bonan, G. B., Levis, S., Kergoat, L., and Oleson, K. W.: Landscape as patches of plant functional types: An integrating concept for climate and ecosystem models, Global Biogeochem. Cy., 16, 5.1-5.23, doi:10.1029/2000GB001360, 2002.

Borga, M., Dalla Fontana, G., Gregoretti, C., and Marchi, L.: Assessment of shallow landsliding by using a physically based model of hillslope stability, Hydrol. Process., 16, 2833-2851, 2002.

Brooks, R. H. and Corey, A. T.: Hydraulic properties pf porous media, Hydrology Paper, Civil Engineering Dep., 1964.

Burton, A. and Bathurst, J. C.: Physically based modelling of shallow landslide sediment yield at a catchment scale, Environ. Geol., 35, 89-99, 1998.

Cabral, M. C., Garrote, L., Bras, R. L., and Entekhabi, D.: A kinematic model of infiltration and runoff generation in layered and sloped soils, Adv. Water Resour., 15, 311-324, doi:10.1016/0309-1708(92)90017-V, 1992.

Capparelli, G. and Versace, I. P.: FLaIR and SUSHI: two mathematical models for early warning of landslides induced by rainfall, Landslides, 8, 67-79, 2010.

Claessens, L., Schoorl, J. M., and Veldkamp, A.: Modelling the location of shallow landslides and their effects on landscape dynamics in large watersheds: An application for Northern New Zealand, Most, 87, 16-27, 2007.

De Vita, P., Reichenbach, P., Bathurst, J. C., Borga, M., Crosta, G., Crozier, M., Glade, T., Guzzetti, F., Hansen, A., and Wasowski, J.: Rainfall-triggered landslides: a reference list, Environ. Geol., 35, 219-233, 1998.

Ewel, J. J. and Whitmore, J. L.: The ecological life zones of Puerto Rico and the U.S. Virgin Islands, Institute of Tropical forestry, Rio Piedras, Puerto Rico, US Forest Service Research Paper, 1973.

Francipane, A., Ivanov, V. Y., Noto, L. V., Istanbulluoglu, E., Arnone, E., and Bras, R. L.: TRIBS-Erosion: A parsimonious physically-based model for studying catchment hydrogeomorphic response, Catena, 92, 216-231, 2012.

Fredlund, D. G., Xing, A., and Barbour, M. D.: The relationship of the unsaturated soil shear strength to the soil water characteristic curve, Can. Geotech. J., 32, 440-448, 1996.

Garcia-Martino, A. R., Warner, G. S., Scatena, F. N., and Civco, D. L.: Rainfall, Runoff and Elevation Relationships in the Luquillo Mountains of Puerto Rico, Caribb. J. Sci., 32, 413-424, 1996.
Garrote, L. and Bras, R. L.: A distributed model for real-time flood forecasting using digital elevation models, J. Hydrol., 167, 279306, 1995.

Harden, C. P. and Delmas Scruggs, P.: Infiltration on mountain slopes: a comparison of three environments, Geomorphology, 55, 5-24, 2003.

Helmer, E. H., Ramos, O. R., Lopez, T. M., Quinones, M., and Diaz, W.: Mapping forest type and lad cover of Puerto Rico, a component if the Caribbean biodiversity hotspot, Caribb. J. Sci., 38, 165-183, 2002.

Hillel, D.: Fundamentals of soil physics, Academic Press, New York, NY, USA, 1980.

Huffaker, L.: Soil Survey of Caribbean National Forest and Luquillo Experimental Forest, Commonwealth of Puerto Rico, USDA, Natural Resources Conservation Service, Washington, DC, 2002.

Ivanov, V. Y.: Effects of Dynamic Vegetation and Topography on Hydrological Processes in Semi-Arid Areas, MIT, 2006.

Ivanov, V., Bras, R. L., and Vivoni, E. R.: Vegetation-Hydrology Dynamics in Complex Terrain of Semiarid Areas: II. EnergyWater Controls of Vegetation Spatio-Temporal Dynamics and Topographic Niches of Favorability, Water Resour. Res., 44, W03430, doi:10.1029/2006WR005595, 2008a.

Ivanov, V. Y., Bras, R. L., and Vivoni, E. R.: Vegetation-Hydrology Dynamics in Complex Terrain of Semiarid Areas: I A Mechanistic Approach to Modeling Dynamic Feedbacks, Water Resour. Res., 44, W03429, doi:10.1029/2006WR005588, 2008b.

Iverson, R. M.: Landslide triggering by rain in ltration, Water Resour. Res., 36, 1897-1910, 2000.

Jetten, V. G., Riezebos, H., Hoefsloot, F., and van Rossum, J.: Spatial variability of infiltration and related properties of tropical soils, Earth Surf. Proc. Land., 18, 477-488, 1993.

Khallili, N. and Khabbaz, M. H.: A unique relationship for the determination of the shear strength of unsaturated soils, Geotechnique, 48, 681-687, doi:10.1680/geot.1998.48.5.681, 1998.

Knapp, B. J.: Infiltration and storage of soil water, in: Hillslope Hydrology, edited by: Kirkby, M. J., Wiley, Chichester: UK, 43-72, 1978.

Larsen, M. C. and Parks, J. E.: How wide is a road? The association of roads and mass-wasting in a forested montane environment, Earth Surf. Proc. Land., 22, 835-848, 1997.

Larsen, M. C. and Simon, A.: A rainfall intensity-duration threshold for landslides in a humid- tropical environment, Puerto Rico, Geogr. Ann. A, 75, 13-23, 1993.

Larsen, M. C. and Torres Sanchez, A. J.: Landslides triggered by Hurricane Hugo in eastern Puerto Rico, September 1989, Caribb. J. Sci., 28, 113-125, 1992.

Larsen, M. C. and Torres-Sánchez, A. J.: The frequency and distribution of recent landslides in three montane tropical regions of Puerto Rico, Geomorphology, 24, 309-331, 1998.

Lepore, C., Kamal, S. A., Shanahan, P., and Bras, R. L.: RainfallInduced Landslide Susceptibility Zonation of Puerto Rico, Environ. Earth Sci., 66, 1667-1681, doi:10.1007/s12665-011-0976-1, 2012.

Lohnes, R. A. and Demirel, T.: Strength and structure of laterites and lateritic soils, Eng. Geol., 7, 13-33, 1973.

Lu, N. and Godt, J.: Infinite slope stability under steady unsaturated seepage conditions, Water Resour. Res., 44, W11404, doi:10.1029/2008wr006976, 2008. 
Meisina, C. and Scarabelli, S.: A comparative analysis of terrain stability models for predicting shallow landslides in colluvial soils, Geomorphology, 87, 207-223, 2007.

Montgomery, D. R. and Dietrich, W. E.: A physically based model for the topographic control on shallow landsliding, Water Resour. Res., 30, 1153-1171, 1994.

Montrasio, L. and Valentino, R.: A model for triggering mechanisms of shallow landslides, Nat. Hazards Earth Syst. Sci., 8, 1149-1159, doi:10.5194/nhess-8-1149-2008, 2008.

Myster, R. W., Thomlinson, J. R., and Larsen, M. C.: Predicting landslide vegetation in patches on landscape gradients in Puerto Rico, Landscape Ecol., 12, 299-307, 1997.

Noto, L., Ivanov, V., Bras, R., and Vivoni, E.: Effects of initialization on response of a fully-distributed hydrologic model, J. Hydrol., 352, 107-125, 2008.

Oberg, A. and Sallfors, G.: Determination of shear strength parameters of unsaturated silts and sands based on the water retention curve, Geotech. Test. J., 20, 40-48, 1997.

Pack, R. T., Tarboton, D. G., and Goodwin, C. N.: SINMAP, a stability index approach to terrain stability hazard mapping. SINMAP user's manual, Terratech Consulting Ltd., 1998.

Rawls, W. J., Brakensiek, D. L., and Saxton, K. E.: Estimation of Soil Water Properties, Transactions American Society of Agricultural Engineers, St. Joseph, MI, 25, 1316-2320, 1982.

Rosso, R., Rulli, M. C., and Vannucchi, G.: A physically based model for the hydrologic control on shallow landsliding, Water Resour. Res., 42, W06410, doi:10.1029/2005WR004369, 2006.

Scatena, F. N. and Lugo, A. E.: Geomorphology, disturbance, and soil and vegetation of two subtropical wet steepland watersheds of Puerto Rico, Geomorphology, 13, 199-213, 1995.

Schellekens, J.: Hydrological processes in a humid tropical rain forest: a combined experimental and modelling approach, Vrije Universiteit - Amsterdam, 2000.

Schuster, R. L. and Highland, L. M.: Socioeconomic and Environmental Impacts of Landslides in the Western Hemisphere, US Geological Survey Open-File Report 01-0276, US Geological Survey, USA, 47 pp., 2001.

Shiels, A. B., West, C. A., Weiss, L., Klawinski, P. D., and Walker, L. R.: Soil factors predict initial plant colonization on Puerto Rican landslides, Plant Ecol., 195, 165-178, 2008.

Sidle, R. C. and Dhakal, A. S.: Potential effects of environmental change on landslide hazards in forest environments, IUFRO Research Series, Oxen, UK, 123-165, 2002.

Sidle, R. C. and Ochiai, H.: Landslides: Processes, Prediction, and Land Use, Water Resources Monograph Series, AGU, Washington, DC, 18, 312 pp., 2006.

Silver, W. L., Scatena, F. N., Johnson, A. H., Siccama, T. G., and Sanchez, M. J.: Nutrient availability in a montane wet tropical forest: Spatial patterns and methodological considerations, Plant Soil, 164, 129-145, 1994.

Simon, A., Larsen, M. C., and Hupp, C. R.: The role of soil processes in determining mechanisms of slope failure and hillslope development in a humid-tropical forest eastern Puerto Rico, Geomorphology, 3, 263-286, 1990.

Simoni, S., Zanotti, F., Bertoldi, G., and Rigon, R.: Modelling the probability of occurrence of shallow landslides and channelized debris flows using GEOtop-FS, Hydrol. Process., 22, 532-545, doi:10.1002/hyp.6886, 2008.
Sivandran, G.: The role of rooting strategies on the eco-hydrology of semi-arid regions, Civil and Environmental Engineering, Massachusetts Institute of Technology, Cambridge, MA, 2012.

Sivandran, G. and Bras, R. L.: Identifying the optimal spatially and temporally invariant root distribution for a semiarid environment, Water Resour. Res., 48, W12525, doi:10.1029/2012wr012055, 2012.

Sivandran, G., Bisht, G., Ivanov, V. Y., and Bras, R. L.: An elevenyear validation of a physically-based distributed dynamic ecohydorological model tRIBS+VEGGIE: Walnut Gulch Experimental Watershed, AGU Fall Conference, San Francisco, CA, 2008.

Smith, T. M., Shugart, H. H., and Woodward, F. I.: Plant functional types: their revelance to ecosystem properties and global change, International Geosphere-Biosphere Programme Book Series, Cambridge University Press, Cambridge, 1997.

Swanston, D. and Schuster, R.: Long-term landslide hazard mitigation programs: structure and experience from other countries, Bulletin of the Association of Engineering Geologists, 26, 109133, 1989.

Tarolli, P., Borga, M., Chang, K. T., and Chiang, S. H.: Modeling shallow landsliding susceptibility by incorporating heavy rainfall statistical properties, Geomorphology, 133, 199-211, 2011.

Taylor, D.: Fundamentals of Soil Mechanics, Soil Science, John Wiley \& Sons, Inc., 1948.

Tsai, T.-L. and Yang, J.-C.: Modeling of rainfall-triggered shallow landslide, Environ. Geol., 50, 525-534, 2006.

Vanapalli, S. K. and Fredlund, D. G.: Comparison of different procedures to predict unsaturated soil shear strength, in: Advances in Unsaturated Geotechnics edited by: Shackelford, C. D., Houston, S. L., and Chang, N., ASCE Geotechnical Special Publication, American Society of Civil Engineers, Utah State University, Logan, Utah, 195-221, 2000.

Vanapalli, S. K., Fredlund, D. G., Pufahl, D. E., and Clifton, A. W.: Model for the prediction of shear strength with respect to soil suction, Can. Geotech. J., 33, 379-392, 1996.

Vivoni, E. R., Ivanov, V. Y., Bras, R. L., and Entekhabi, D.: Generation of triangulated irregular networks based on hydrological similarity, J. Hydrol. Eng., 9, 288-302, 2004.

Vivoni, E. R., Ivanov, V. Y., Bras, R. L., and Entekhabi, D.: On the effects of triangulated terrain resolution on distributed hydrologic model response, Hydrol. Process., 2122, 2101-2122, 2005.

Waide, R. B., Zimmerman, J. K., and Scatena, F. N.: Controls of Primary Productivity: Lessons from the Luquillo Mountains in Puerto Rico, Ecology, 79, 31-37, 1998.

Walker, L. R. and Shiels, A. B.: Post-disturbance erosion impacts carbon fluxes and plant succession on recent tropical landslides, Plant Soil, 313, 205-216, 2008.

Walker, L. R., Zarin, D. J., Fetcher, N., Myster, R. W., and Johnson, A. H.: Ecosystem development and plant succession on landslides in the Caribbean, Biotropica, 28, 566-576, 1996.

Wang, H., Hall, C. A. S., Scatena, F. N., Fetcher, N., and Wu, W.: Modeling the spatial and temporal variability in climate and primary productivity across the Luquillo Mountains, Puerto Rico, Forest Ecol. Manage., 179, 69-94, 2003.

Weaver, P. L. and Murphy, P. G.: Forest Structure and Productivity in Puerto Rico's Luquillo Mountains, Biotropica, 22, 69-82, 1990.

Wu, W. and Sidle, R.: A distributed slope stability model for steep forested basins, Water Resour. Res., 31, 2097-2110, 1995. 
Yang, Z. L., Dickinson, R. E., Henderson-Sellers, A., and Pitman, A. J.: Preliminary study of spin-up processes in land surface models with the first stage data of Project for Intercomparison of Land Surface Parameterization Schemes Phase 1(a), J. Geophys. Res.-Atmos., 100, 16553-16578, doi:10.1029/95jd01076, 1995.
Yeh, H., Chan, P., Chen, J., and Lee, C.: Insability of unsaturated soil slopes due to infiltration, Internation Symposium on Geohazards Mitigation, Tainan, Taiwan, 2006. 